\title{
Cost of Quality (CoQ) of Water Testing Laboratory
}

\author{
Afshan Bhatti ${ }^{1}$, Sohail Anwar ${ }^{2}$ Mohammed Atiq ${ }^{3}$ \\ Hamdard University, Pakistan
}

\begin{abstract}
The purpose of the study is to classify and determine different quality cost and the quantity of such errors in accreditated water testing laboratory. The study indicates that the quality of water testing laboratory, test results can be regarded as good based on the accuracy of the result. In this study total cost of quality is $9.33 \%$ from revenues which is not more and COC is $6.93 \%$ and CONC is $2.4 \%$.This is an ideal situation, prevention costs will be the largest portion of the Total Cost of Quality. All costs resulting from services not conforming to requirements of customer/user needs which occur after delivery of test report. By minimizing delay and Claims (retest) can reduced external failure cost Laboratory given weighted to customer needs because of the good quality of service. Although, laboratory require improvements in providing test results without delay to the customer. The cost of processing and correcting such errors was minimum. The use of a customer feedback system allows systematic monitoring of external failures. The fundamental point is to monitor the effects of the quality measures taken to reduce the number of failures. The method implemented this study is the classical prevention-appraisal-failure $(P-A-F)$ model.
\end{abstract}

Keywords: Quality, Cost of Quality (CoQ), Cost of conformance (COC), Cost of non-conformance (CONC), Water testing laboratory

\subsection{COQ History:}

\section{Introduction:}

Joseph Juran first discussed cost of quality analysis in 1951 in the first edition of Quality Control Handbook. [1] Armand Feigenbaum identified the four cost categories in 1956 in "Total Quality Control" in the Harvard Business Review,Vol. 34, No 6.He says "In process improvement efforts, quality costs or cost of quality is a means to quantify the total cost of quality-related efforts and deficiencies". Philip B. Crosby in his book Quality Is Free, the cost of quality has two main components. These are cost of good quality (or the cost of conformance) and the cost of poor quality (or the cost of non-conformance).The cost of poor quality affects internal and external costs resulting from failing to meet requirements. The cost of good quality affects costs for investing in the prevention of non-conformance to requirements. Costs for appraising a product or service for conformance to requirements. [2]

\subsection{Cost of Quality:}

The total quality costs are the sum of prevention, appraisal and failure costs. They represent the difference between the actual cost of a product or service and the potential (reduced) cost given no substandard service or no defective products. [15 ]Quality costs are important considerations for information management and information technology. In global world, the most important way to survive in the competitive environment for firms is using quality as a core strategy.[3].COQ programs provide a good method for identification and measurement of quality costs, and thus allow targeted action for reducing the COQ and thus improving the quality. Types of COQ are,

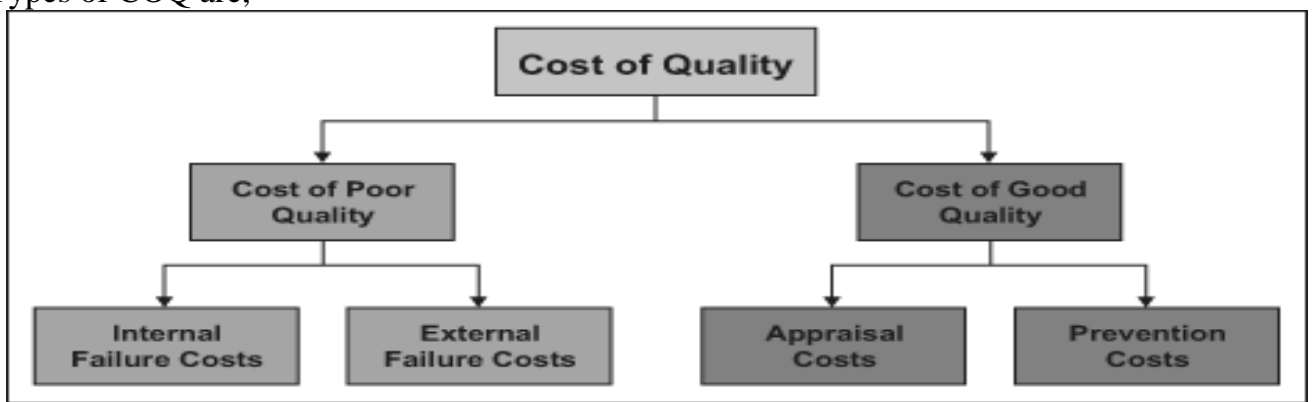

Figure 1:Types of COQ

The iceberg model is very often used to illustrate this matter. Only a minority of the costs of poor and good quality is obvious - appear above the surface of the water. But there is a huge potential for reducing costs under the water. Identifying and improving these costs will significantly reduce the costs of doing business. [3]. A 
reasonable amount of detailed information on various methods of categorization, collection and measurement of quality costs can be found in the literature (Plunkett and Dale,1987; Williams et al., 1999; Schiffauerova and Thomson, 2004). However, there are only a few published, practical examples from industry that give specifics about the costs that are included or excluded in quality costing and about how the costs are practically collected and measured. More detailed descriptions of CoQ systems from industry can be found in Whitehall (1986),Hesford and Dale (1991) and Purgslove and Dale (1996). This paper intends to contribute to this area by providing an analysis of the quality costing practices of four successful companies. It is also the model that will be referred to throughout this thesis. In his P-A-F model formulation, Feigenbaum [14] divided CoQ into the three interrelated categories of prevention, appraisal and failure costs. "COPQ is the sum of all costs that would disappear if there were no quality problems."-Juran"You can easily spend $15-30 \%$ of your sales dollars on PONC." - Crosby "In most companies the costs of poor quality runs at $20-30 \%$ of sales." - Juran

\subsection{COQ in Water Testing Laboratory:}

With the new manufacturing concept, the cost of quality is becoming an indispensable element of the production /Service Industry. Many successful companies take the quality as the central value and consider it to be a crucial success element for gaining a competitive advantage. Any serious attempt to improve quality must take into account the costs associated with achieving quality since the objective of continuous improvement programs is not only to meet customer requirements, but also to do it at the lowest cost. Therefore, measuring and reporting the cost of quality (CoQ) should be considered an important issue for managers. (Schiffauerova and Thomson, 2006). In this study calculate CoQ for water testing laboratory (Accreditated). How much we should pay in rupees to achieve quality drinking water testing Laboratory and what factors should be considered in water testing laboratory. Usually in testing labs ISO-17025 applicable. How to improve water testing laboratory and want to get quality testing. In this study significant and non-significant factors are discussed. Calculating CoQ for water testing laboratory. This research purpose is to minimize cost of testing and get better quality testing results and also discuss what minimum important requirement (Equipment, Reagents, and Chemicals etc.) for water testing labs .Karachi water testing laboratory is discussed in this study. The most essential point is to monitor the effects of the quality measures taken to reduce the number of failures. [13]

\section{Research Methodology:}

In this study accreditated, Karachi water testing laboratory COQ calculated and discussed laboratory provides quality results. Useful tests are available to help determine the health and safety of a water supply. Local health department can assist in selecting tests important for assessing your drinking water. WHO recommend following tests for water.

Table 1:WHO Parameter Water Testing

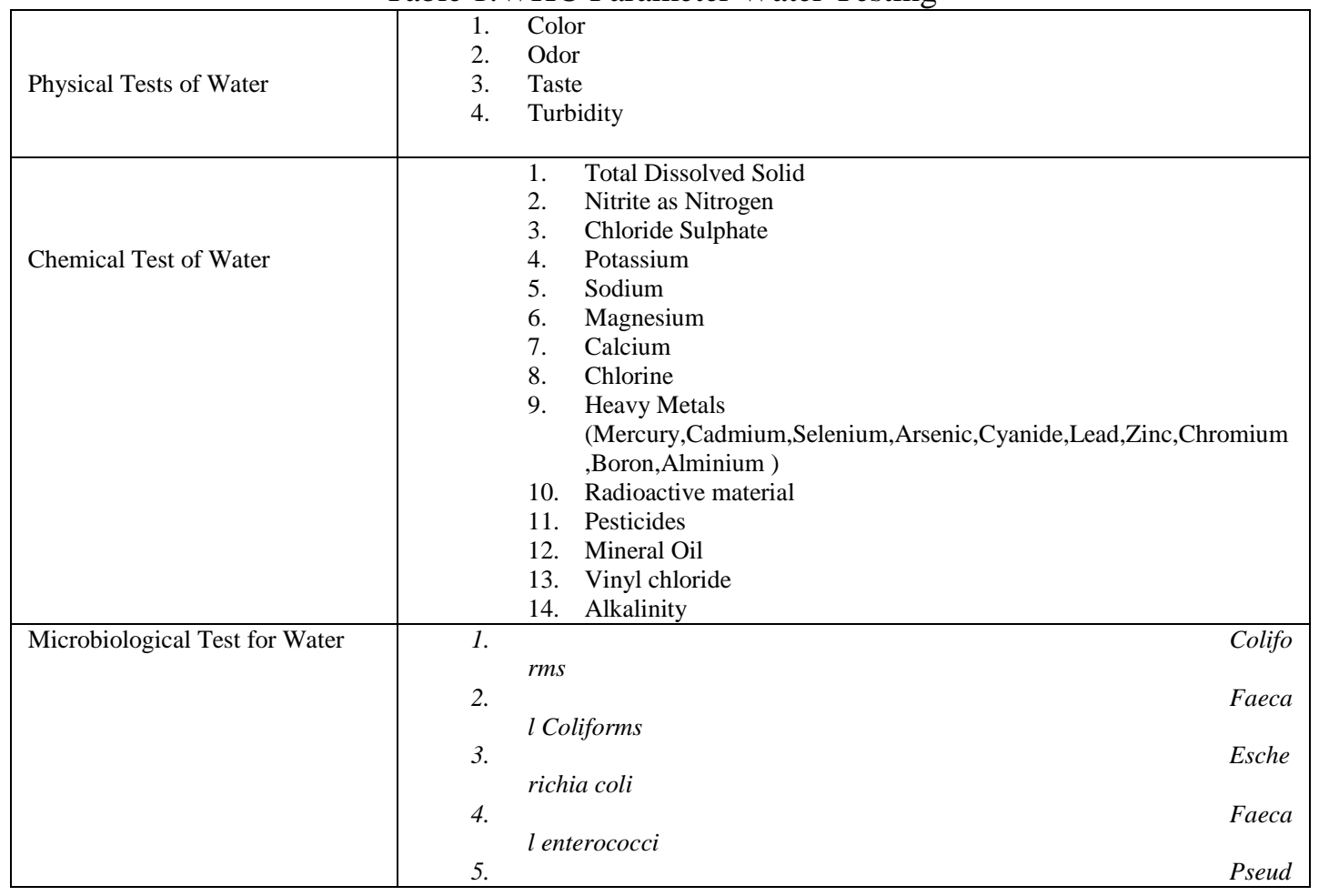




\begin{tabular}{|r|rr|}
\hline 6. & omonas aeruginosa & Total \\
7. & Viable Plate Count at 22 C & Total \\
& Viable Count at 36 C & \\
\hline
\end{tabular}

Table 2:Examples of Quality Costs Associated with Water Testing Laboratory

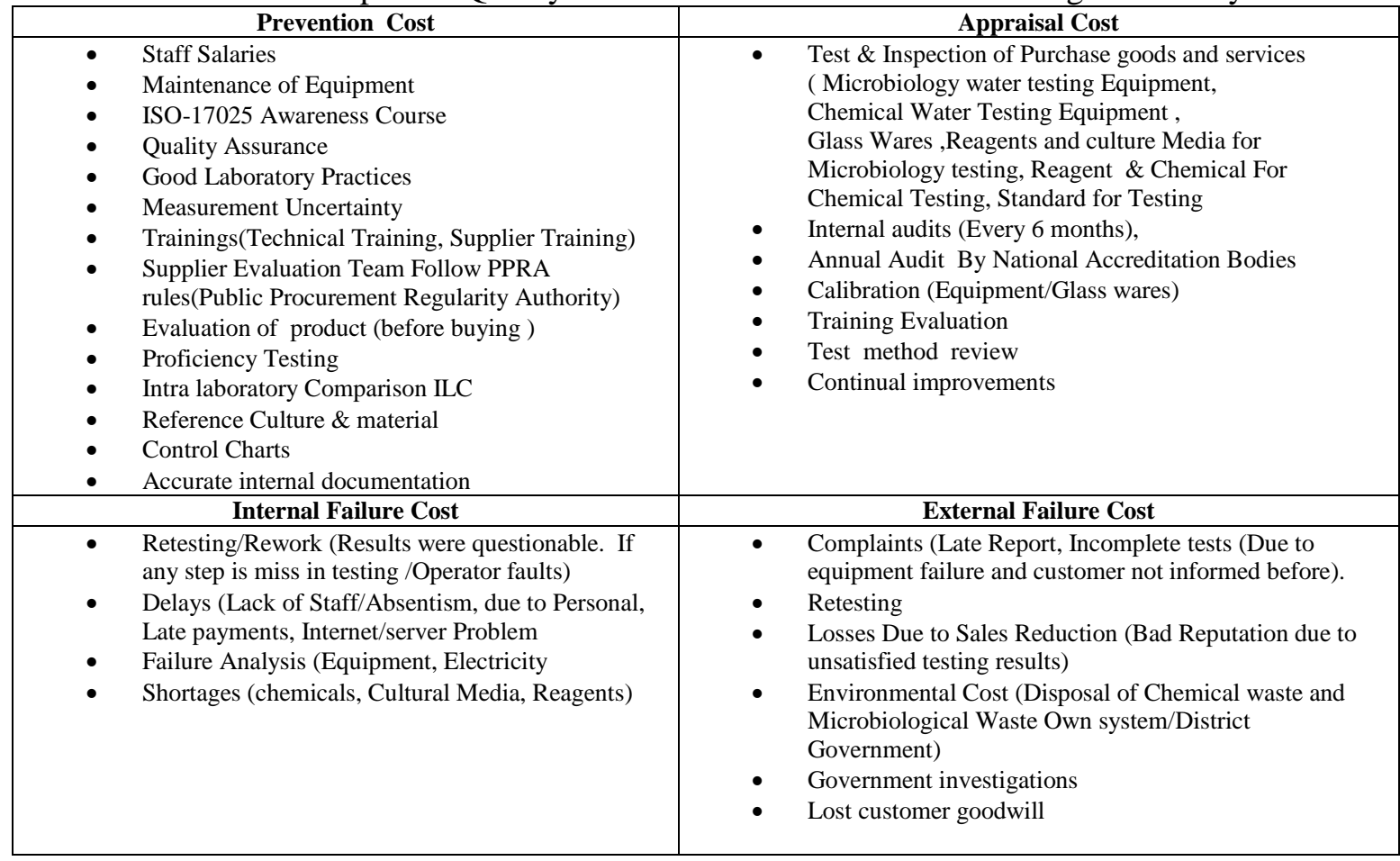

Table 3: Ratios of each COQ Category to Revenues and Total Quality Costs of a Year 2012 Karachi Water Testing Laboratory ISO-17025 Accreditated

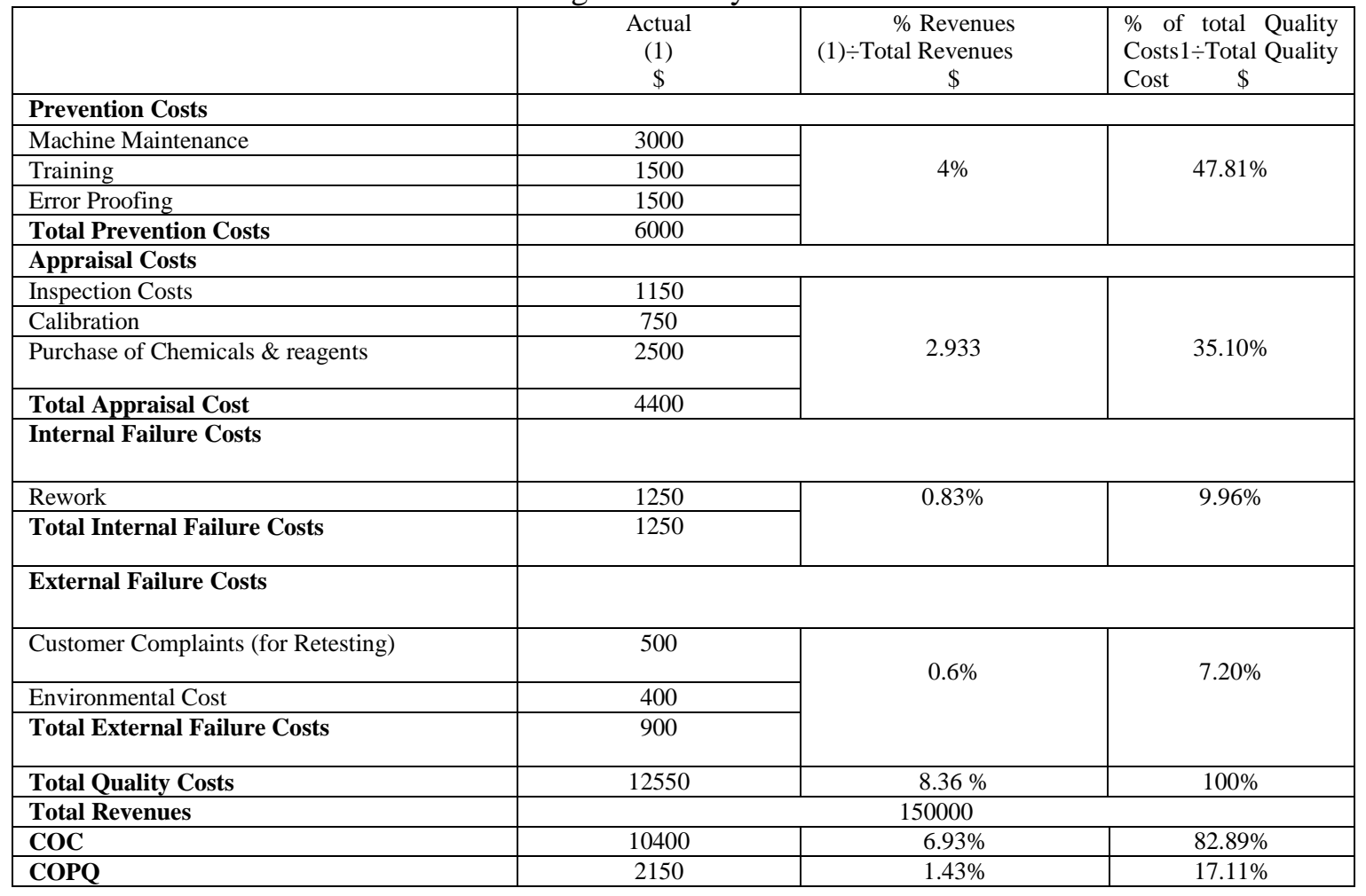




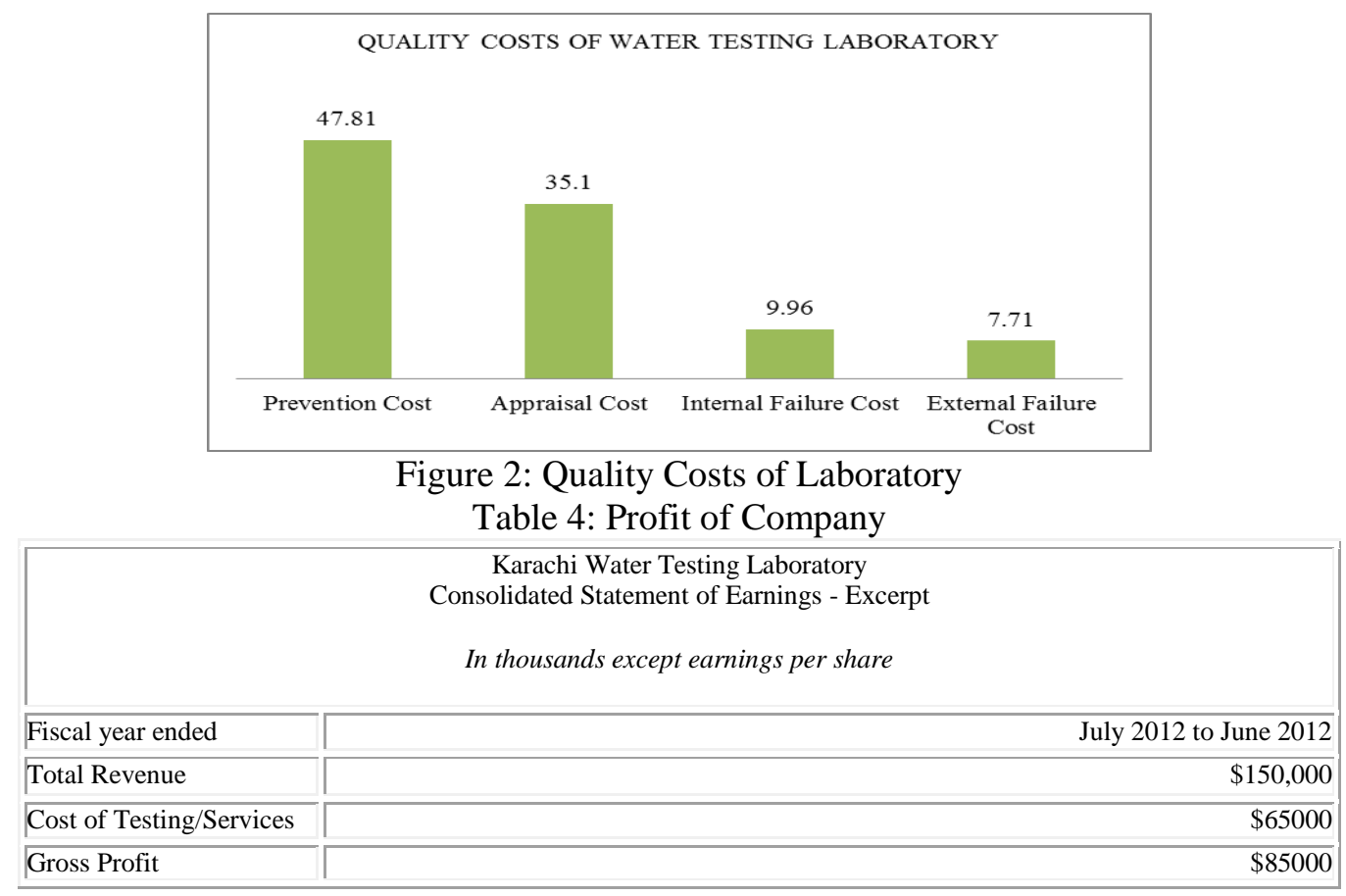

Consolitated Statment of Earning July 2011 to June 2012

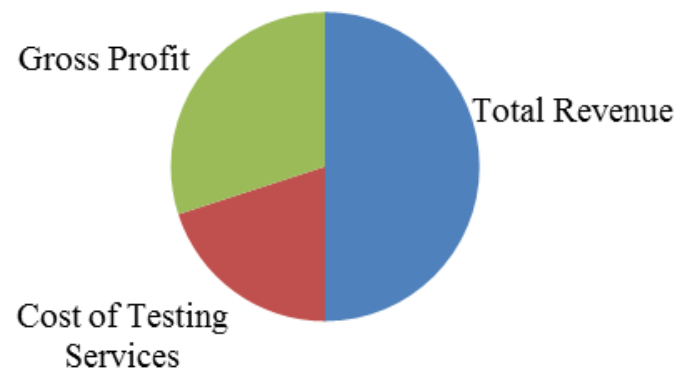

Figure 3: Graphical Presentation of Consolidated Statement of Earning

In this study cost of quality is $9.33 \%$ from revenues which is not more and COC is $6.93 \%$ and CONC is $2.4 \%$. Prevention costs is the largest portion of the Total Cost of Quality Which is $47.81 \%$. Appraisal costs should be the second largest category, but should not exceed prevention costs and internal failure cost .All costs resulting from services not conforming to requirements or customer which occur before delivery of product, or the furnishing of a service. Examples include rework, retesting. The goal is to identify all internal failures and resultant costs, and then systematically identify and eliminate root causes until internal failure costs are eliminated external failure cost. By minimizing delay and Claims (retest) can reduced external failure cost. The training programs or awareness programs which are important can be strengthened to have a control on the preventive costs. More emphasis can be given to the preventive measures and activities. Code inspections and testing can be strengthened to have a control on the Appraisal costs.

\section{Discussion:}

Now days, increasing in competitive environment at both national and international level forced the businesses to produce customer-based and also this environment has forced the businesses to provide quality to satisfy the customer needs. The model use in this study is the classical prevention-appraisal-failure (P-A-F). The study indicates that the quality of laboratory test results can be regarded as good based but improvements are required in test results without delay. The cost of processing and correcting such errors was negligible. Laboratory taken systematic quality initiatives; however, a formal cost of quality $(\mathrm{CoQ})$ methodology was only employed. As each cost factors affects the other, a systematic approach is needed to recognize both the effects of factors on each other and quality level of products /services. The article explains the benefits of the eventual adoption of a $\mathrm{CoQ}$ approach in water laboratory, proper frame work and we say that guideline for significant and non-significant factors which should consider in quality testing laboratory. Laboratory knows exactly what 
its conformance and non-conformance costs are. At the same time, they adopt systematic quality improvement programs in order to reach a zero defect quality level. Conformance costs are consequently given much less attention in the quality management programs and measuring them together with the cost of non-conformance. It has been suggested that the cost of poor quality can range from $15 \%-40 \%$ of business costs. [6]

\section{Conclusion:}

In recent years organizations have been focusing much attention on quality management. To maximize the profits of an organization it is necessary to monitor quality costs. Karachi Water Laboratory has a strong quality strategy in order to survive in the competitive world. Focusing on Prevention and appraisal cost this company reduced all type failures which lead to increase profit and good reputation in market. Laboratory focus on COC and decrease CONC. Cost of quality has a powerful based on the effect of quality costs on the level of customer satisfaction; it has been proved that increasing prevention costs and decreasing external failure costs can directly improve the level of customer satisfaction. Cost of quality has also direct effect on service cost and indirect effect on Profitability. In order to improve quality an organization must take into account the costs associated with achieving quality since the objective of continuous improvement programs is not only to meet customer requirements, but also to do it at the lowest cost. A realistic estimation of quality costs is an essential element of any TQM initiative. CoQ focuses on process improvement and the elimination of all forms of waste. Laboratory measure, monitor and work mostly with the cost of non-conformance. This program mainly facilitates identification of the target areas for quality improvement and cost reduction in quality effort The methodology is not complex. CoQ decrease defects, overall costs, customer complaints and increase sales, profit, capacity, customer satisfaction, employee satisfaction This CoQ programs provide a good method for identification and measurement of quality costs, and thus allow targeted action for reducing CoQ. Further education on the practical level is needed for managers to understand better the CoQ concept in order to appreciate fully the benefits of the approach, to increase their ability to implement a CoQ measurement system and to save money.

\section{References:}

[1]. Juran, J.M., Quality Control Handbook. 1st ed. 1951, New York, NY: McGraw-Hill

[2]. Crosby, P.B., Quality is Free. 1979, New York, NY: McGraw-Hill

[3]. A Theoretical Approach to the Concept of the Costs of Quality Yrd. Doç. Dr. Yakup DURMAZ Hasan Kalyoncu Üniversitesi İktisadi ve İdari Bilimler Fakültesi Dekan Yardımcısı ve İşletme Bölüm Başkanı Havaalanı Yolu Üzeri 8. Km. ŞahinbeyGAZIANTEP

[4]. Analysing the Cost Factors on Total Cost of Quality: A System Dynamics Approach Behdad kiani Green Research Center, Iran University of Science \& Technology, Tehran.

[5]. A project management quality cost information system for the construction industry Peter E.D. Lovea, *, Zahir Iraniba We-B Centre, School of Management Information Systems, Edith Cowan University, Churchlands, Perth, WA 6018, AustraliabDepartment of Information Systems and Computing, Brunel University, Uxbridge.

[6]. Cost of Quality Analysis: Driving Bottom-line Performance Mohandas V.P. and Sankara Raman Sankaranarayanan

[7]. Cost Of Quality Models And Their Implementation In Manufacturing Firms International Journal for Quality research UDK005.642.3:338.3 N.M. Vaxevanidis1) G. Petropoulos2) J. Avakumovic3) A. Mourlas4)

[8]. A Review of Research on Cost of Quality Models and Best Practices Andrea Schiffauerova *, Vince Thomson *** École Polytechnique de Montréal, Department of Mathematics and Industrial Engineering, Montreal ** Department of Mechanical Engineering, McGill University, Montreal, Canada

[9]. Cost of quality tradeoffs in manufacturing process and inspection strategy selection by Hadi Zaklouta Bachelor of Science in Materials Science and Engineering Massachusetts Institute of Technology, 2009

[10]. Economic case of Quality Measuring the cost of Quality for Management by Gary Cokins

[11]. Cost of Quality: A Survey of Models and Best Practices Andrea Schiffauerova, Vince Thomson McGill University

[12]. External failures as descriptor of quality in clinical microbiology laboratory services. Saarela U, Kivinen T, Sarkkinen H. Source Medical Services Division, Päijät-Häme Central Hospital, Lahti, Finland

[13]. Feigenbaum, A.V., Total Quality Control. Harvard Business Review, 1956. 34(6): p. 93-101

[14]. Excerpted from the ASQ Quality Costs Committee, Principles of Quality Costs: Principles, Implementation, and Use, Third Edition, ed. Jack Campanella, ASQ Quality Press, 1999, pages 3-5 